\title{
Electrochemical Evaluation of Biologically Modified Carbon Paste Electrode with Cyclic Voltammetric Technique
}

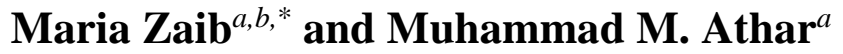 \\ ${ }^{a}$ Institute of Chemistry, University of Punjab, Lahore-54590, Pakistan \\ ${ }^{b}$ Department of Chemistry, Government College Women University, Sialkot-51310, Pakistan
}

Received October 27, 2016; accepted September 15, 2018

\begin{abstract}
A carbon paste electrode has been modified with a red algal species of Porphyridium cruentum, and the characterization of its electro catalytic activity has been done with cyclic voltammetric studies of the potassium ferricyanide $\left(\mathrm{K}_{3}\left[\mathrm{Fe}(\mathrm{CN})_{6}\right]\right)$ system. In order to highlight the electrode's stable and fast response to the $\left[\mathrm{Fe}(\mathrm{CN})_{6}\right]^{3-} /\left[\mathrm{Fe}(\mathrm{CN})_{6}\right]^{4-}$ redox couple, experiments were also conducted with a bare carbon paste electrode. FTIR spectra revealed the functional moieties of the bare and modified electrodes. The electrochemical surface area and surface coverage capacity were calculated for both electrodes. The effect of the scan rate helped to evaluate the nature of the electrode process, electron transfer mechanism, and kinetic parameters (rate constant and charge transfer coefficient).
\end{abstract}

Keywords: red algal species, carbon paste electrode, cyclic voltammetry, scan rate and FTIR.

\section{Introduction}

In the recent years, many analytical techniques, which are available to analytical chemists, have provided high sensitivity and selectivity. However, most of these methods require sophisticated instrumentation, trained operators and time consuming chemical manipulation of the samples before analysis [1]. Electrochemistry has an edge over these techniques, as it is inexpensive, extremely sensitive and suitable for large scale monitoring of electrochemically active environmental pollutants [2]. In the field of electrochemistry, scientists keep on searching new electrode materials with wide potential window, high signal to noise ratio and mechanical stability, which enable their application in flowing systems, and resistance to the surface fouling or passivation. The last parameter was mainly focused, as the available electrode material was mostly subjected to the surface fouling, thus causing hindrance in its application in complex matrices [3]. Carbon paste electrodes (CPE) have attracted attention due to a number of advantages over macro or membrane electrodes. They have

\footnotetext{
* Corresponding author. E-mail address: mariaa.zaib@gmail.com
} 
chemical inertness, robustness, stable response, low ohmic resistance, require no internal solution and have greater applicability [4]. Moreover, they are non-toxic and environment friendly electrode materials, and the problem of passivation, in this case, is simply solved by an easy renewal of their surface. Carbon paste electrodes have been used in electro analysis as a non-expensive and reliable methodology for the screening of a number of environmental contaminants [5].

With the passage of time, CPE have undergone impressive development, and new innovations keep on improving its electro catalytic activity and aiding the electrochemical process [6]. One such innovation was the advent of chemically and biologically modified carbon paste electrodes. In these electrodes, the modifier can be mixed through a number of methods such as mechanical admixing, dissolution etc. [7]. According to Kalcher [8], these modifiers perform one of the following four main functions:

- preferential attachment of desired species (stripping analysis);

- mediation of electrode's surface via immobilization;

- intervention in catalytic phenomena;

- alteration of the surface characteristics of the carbon paste electrode.

Among these modified carbon paste electrodes, chemically modified ones have gained persistent attention, as compared to those based on biological materials. In these chemically modified carbon paste electrodes, a diverse variety of complexing agents is available for the selective determination of the analyte. On the other hand, biological material like fungi, algae or lichen can also be a potent source of modification. For years, these microbial biomasses have played a considerable role in biosorption studies of a number of environmental pollutants [9]. These microorganisms effectively bind these contaminants through biosorptive sites involving chemical processes of adsorption, covalent bonding and ion exchange. These biosorptive sites are functional moieties such as carboxyl, hydroxyl, amino and phosphate groups usually present on the cell wall structure [10].

In our previous work, a carbon paste electrode modified with Porphyridium cruentum has been reported for stripping analysis of As (III) [11]. In the present study, cyclic voltammetry has been used to illustrate the mechanism of electrode reaction, electrochemical surface area and kinetic parameters of this modified carbon paste electrode, through one electron oxidation/reduction system of potassium ferricyanide. This redox couple has been a popular choice through the years, as it exhibits a nearly reversible electrode reaction without any complication of the proceedings or post chemical reactions [12].

Cyclic voltammetry is the most helpful tool in studying the reaction process and kinetics on the electrode surface. Cyclic voltammetry is always considered a more appropriate tool than polarography, for studying homogeneous redox catalysis, as the recording of the current potential relation is much faster, and the control of the diffusion process is more accurate, and involves a wider range of rates [13]. 


\section{Material and method}

Reagents and solutions

All the reagents used in this study were of analytical grade. Graphite powder and mineral oil were purchased from Alfa Aesar and MP Biomedicals, respectively. Potassium ferricyanide and potassium chloride salts were provided by Sigma.

\section{Equipment}

The current-voltage measurements were performed with a potentiostat (Ref 600 TM, Gamry, Germany) at room temperature $\left(25^{\circ} \mathrm{C}\right)$. It was interfaced by a PC with Gamry Framework software to run the cyclic voltammetric experiments. Gamry EChem Analyst and My Gamry Data software were used for data acquisition and interpretation. Bob's cell was employed as a voltammetric cell. This is a system of three electrodes in which a modified carbon paste electrode served as working electrode. Saturated calomel electrode (SCE) and platinum wire were taken as reference and counter electrodes, respectively.

\section{Preparation of modified and bare carbon paste electrode}

A modified carbon paste electrode was prepared by mixing graphite powder, mineral oil and freeze dried $P$. cruentum biomass in the $w / w$ ratio of 65:30:5. The mixture was uniformly mixed and then packed into the electrode body (plastic syringe, i.d. $5 \mathrm{~mm}$ ). Electrical contact was achieved by inserting a copper wire, and the surface was smoothened on a shiny weighing paper. The bare carbon paste electrode was made up of just graphite powder and mineral oil (70:30), and prepared as discussed above.

\section{Surface characterization of bare and modified electrode with FTIR spectra}

The surface characterization of bare and modified electrodes was performed via Fourier Transform Infrared Spectroscopy (FTIR), with attenuated total reflectance (ATR) in the solid phase within the range of 2000 - 3000 wave numbers $\mathrm{cm}^{-1}$ (Alpha Bruker, Germany). The data obtained from FTIR-ATR spectra were evaluated with OPUS 5.5 software.

\section{Results and discussion}

\section{Surface characterization of bare and modified electrode with FTIR spectra}

In the case of both modified and bare carbon paste electrodes (Fig. 1a), two consecutive absorption bands appeared at $2965 \mathrm{~cm}^{-1}$ and $2884 \mathrm{~cm}^{-1}$, which can be attributed to $-\mathrm{C}-\mathrm{CH}_{3}$ and $\equiv \mathrm{CH}$ groups, respectively [14]. Unlike the bare electrode, a band appeared at $2100 \mathrm{~cm}^{-1}$ in the modified one, which is due to triple bond configuration, most probably, of the terminal alkyne group. Moreover, a single band at $2190 \mathrm{~cm}^{-1}$ in the bare carbon paste electrode indicated a medial alkyne group [15]. This single band was converted to doublet in the modified electrode. 


\section{Electrochemical behavior of bare and modified electrodes}

The electrochemical behavior of $P$. cruentum based modified carbon paste electrode (MCPE) and bare carbon paste electrode (BCPE) was studied by cyclic voltammetry using electrocatalytic properties of potassium ferricyanide $\left[\mathrm{K}_{3} \mathrm{Fe}(\mathrm{CN})_{6}\right]$. Fig. 1b shows the cyclic voltammograms of MCPE and BCPE in a $5 \mathrm{mM} \mathrm{K}_{3} \mathrm{Fe}(\mathrm{CN})_{6}$ solution with $0.1 \mathrm{M} \mathrm{KCl}$ as the supporting electrolyte.
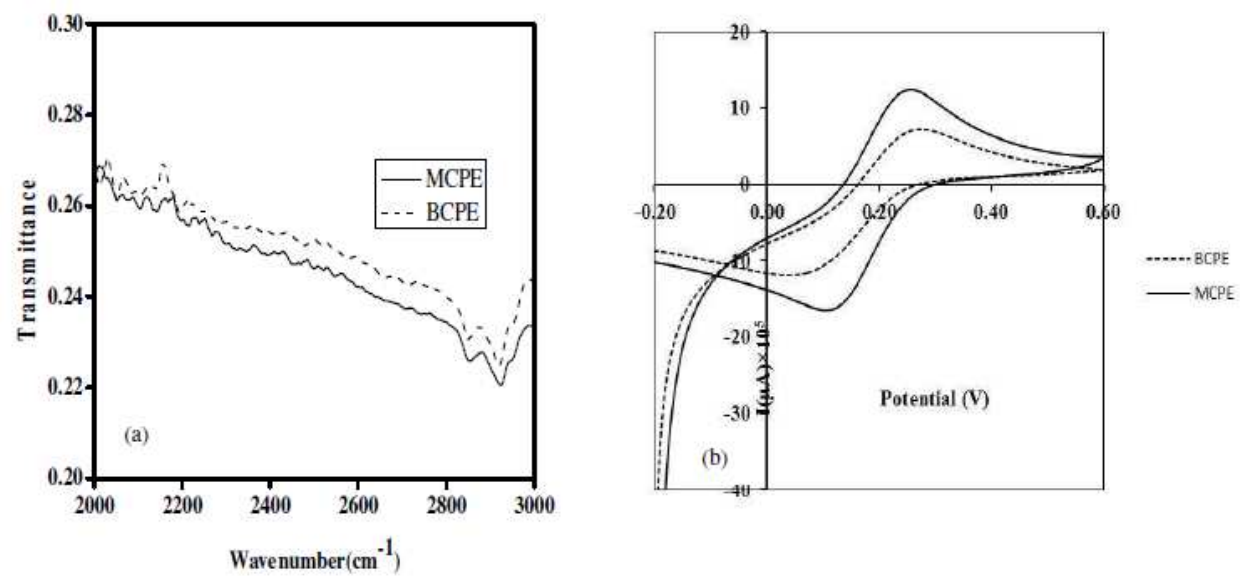

Figure 1. (a) FTIR spectra of modified (MCPE) and bare (BCPE) carbon paste electrodes. (b) Cyclic voltammograms of modified (MCPE) and bare (BCPE) carbon paste electrodes in a $5 \mathrm{mM} \mathrm{K}{ }_{3} \mathrm{Fe}(\mathrm{CN})_{6} / 0.1 \mathrm{M} \mathrm{KCl}$ system.

It is clear from the above mentioned figure that the cyclic voltammogram exhibits an anodic peak at a forward scan of the potential related to the oxidation of the $\mathrm{Fe}^{2+} \rightarrow \mathrm{Fe}^{3+}$ reaction, whereas at a reverse scan of the potential, a cathodic peak appeared due to the reduction of $\mathrm{Fe}^{3+}$ back to $\mathrm{Fe}^{2+}$. MCPE gave more defined peaks as compared to the bare one.

In the case of MCPE, peaks related to $\mathrm{Fe}^{2+} / \mathrm{Fe}^{3+}$ redox couple can be observed at $\mathrm{Epa}=104 \mathrm{mV}$ and $\mathrm{Epc}=258 \mathrm{mV}$, along with a peak potential separation of $\Delta \mathrm{E}$ $=154 \mathrm{mV}$.

As it can be seen, the peak separation is greater than $(59 / \mathrm{n}) \mathrm{mV}$, which is the peak separation value for a reversible reaction. This suggests that the $\mathrm{Fe}^{2+} / \mathrm{Fe}^{3+}$ redox couple on MCPE showed a quasi- reversible behavior [16].

\section{Electrochemical area of the electrodes}

The area of MCPE and BCPE was calculated according to the following Randles Sevcik formula for a reversible process [17]:

$$
\mathrm{I}_{p}=0.4463 \times\left(\frac{F^{3}}{R T}\right)^{1 / 2} \times n^{3 / 2} \times A_{0} \times D_{0}^{1 / 2} \times C u^{1 / 2}
$$

where $I_{p}$ refers to the peak current, $n$ is the number of electrons transferred, $A_{o}$ is the surface area, $D_{0}$ is the diffusion coefficient, $v$ is the scan rate and $C$ is the concentration, respectively. Here, for $5 \mathrm{mM} \mathrm{K}_{3} \mathrm{Fe}(\mathrm{CN})_{6}$ in a $0.1 \mathrm{M} \mathrm{KCl}$ electrolyte, $\mathrm{T}=298 \mathrm{~K}, \mathrm{R}=8.314 \mathrm{~J} / \mathrm{Kmol}, \mathrm{F}=96480 \mathrm{C} / \mathrm{mol}, \mathrm{n}=1$ and $\mathrm{D}_{\mathrm{o}}=7.6$ $\times 10^{-6} \mathrm{~cm}^{2} / \mathrm{s}$. From the slope of the plot (Fig. 2 a and c) drawn between $\mathrm{I}_{\mathrm{pa}}(\mu \mathrm{A})$ and $v^{1 / 2}(\mathrm{mV} / \mathrm{s})^{1 / 2}$, the electro active area was calculated by applying Eq. 1 . In our 
experiments, the areas for MCPE and BCPE are $0.574 \mathrm{~cm}^{2}$ and $0.1509 \mathrm{~cm}^{2}$, respectively.
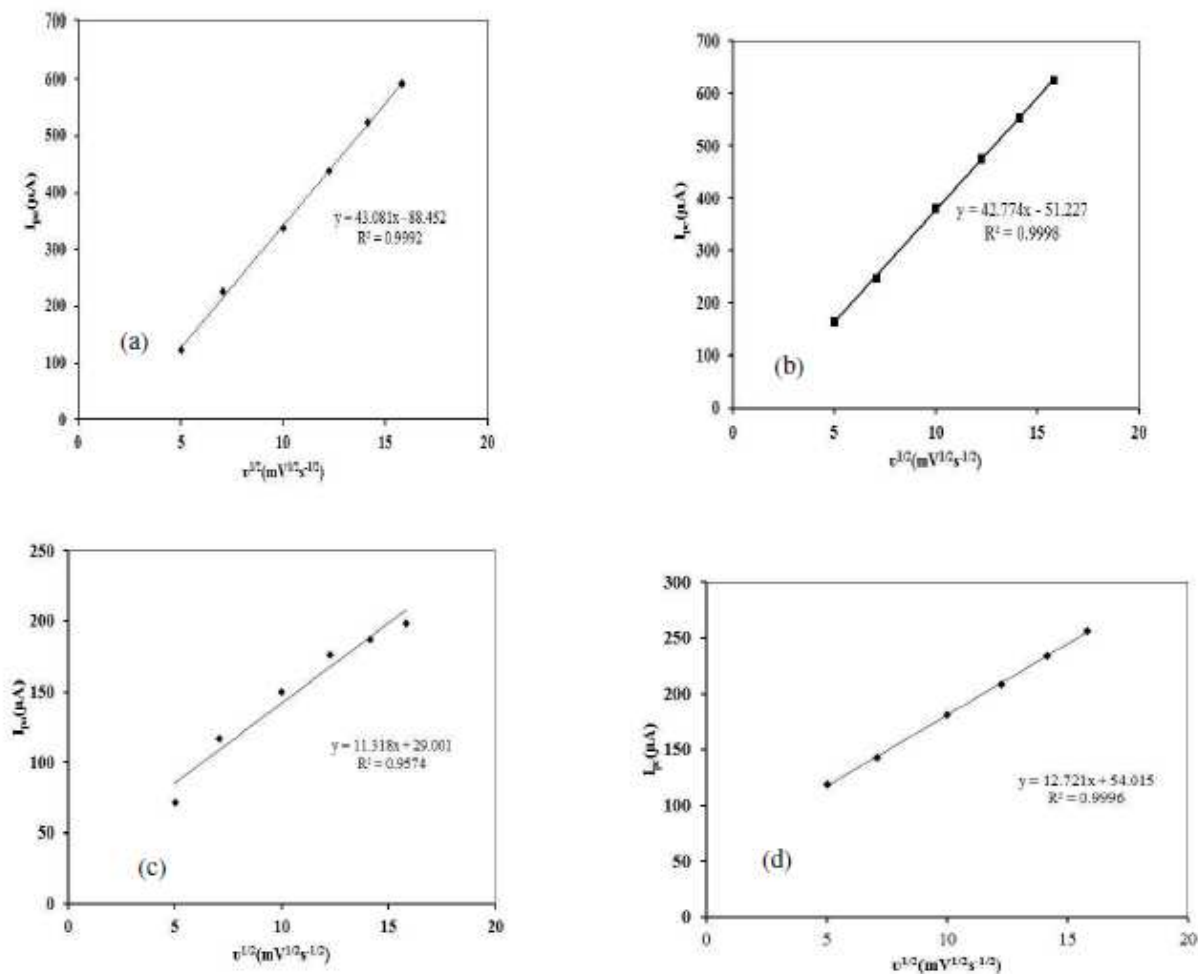

Figure 2. Plot of anodic and cathodic peak current $(\mu \mathrm{A}) v s$. square root of scan rate $(\mathrm{mV} / \mathrm{s})^{1 / 2}$ for $(\mathbf{a}$ and $\mathbf{c})$ modified and $(\mathbf{b}$ and $\mathbf{d})$ bare carbon paste electrodes.

\section{Effect of scan rate}

The effect of varying scan rates on the cyclic voltammograms of $5 \mathrm{mM}$ $\mathrm{K}_{3} \mathrm{Fe}(\mathrm{CN})_{6}$ using $\mathrm{MCPE} / \mathrm{BCPE}$ in a $0.1 \mathrm{M} \mathrm{KCl}$ supporting electrolyte was studied within the range of $25-250 \mathrm{mV} / \mathrm{s}$. A linear correlation between the redox peak currents $(\mu \mathrm{A})$ and the square root of scan rate $(\mathrm{mV} / \mathrm{s})^{1 / 2}$ is shown in Fig $2 \mathrm{a}-$ d. According to Randles Sevcik equation for the peak current, it is predicted that this kind of behavior corresponds to an electrochemical process (i.e. mass transport) dependent on the electrode potential and diffusion [18]. This linear correlation indicated a reversible reaction limited by mass transport to the surface of the modified electrode [19]. The electro active species have to reach the electrode surface by diffusion, for the electron transfer to occur. It means that the electron transfer is controlled by mass transport, although the whole process is governed by diffusion. The equations for MCPE (Eqs. 2 and 3) and BCPE (Eqs. 4 and 5) are given below:

for MCPE, 


$$
\begin{aligned}
& \mathrm{I}_{p a}(\mu A)=43.08 \mathrm{u}^{1 / 2}\left(\mathrm{mV}^{1 / 2} s^{-1 / 2}\right)-88.452, r^{2}=0.9992 \\
& \mathrm{I}_{p e}(\mu A)=42.77 \mathrm{v}^{1 / 2}\left(m V^{1 / 2} s^{-1 / 2}\right)-51.227, r^{2}=0.9998
\end{aligned}
$$

for BCPE,

$$
\begin{aligned}
& \mathrm{I}_{p a}(\mu A)=11.318 \mathrm{v}^{1 / 2}\left(\mathrm{~m}^{1 / 2} \mathrm{~s}^{-1 / 2}\right)+29.001, r^{2}=0.9574 \\
& \mathrm{I}_{p o}(\mu A)=12.721 \mathrm{v}^{1 / 2}\left(\mathrm{mV}^{1 / 2} \mathrm{~s}^{-1 / 2}\right)+54.051, r^{2}=0.9996
\end{aligned}
$$
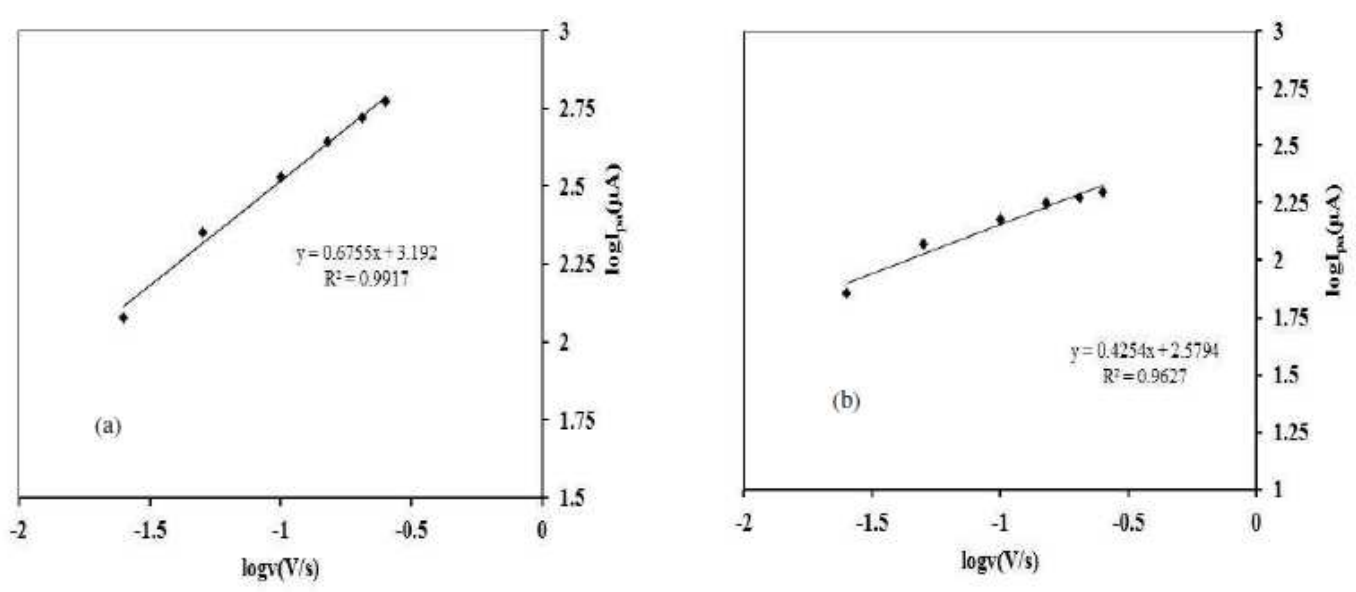

Figure 3. Plot between logarithm of peak current $(\mu \mathrm{A})$ and logarithm of scan rate $(\mathrm{V} / \mathrm{s})$ for (a) modified and (b) bare carbon paste electrodes.

A plot of logarithm of peak current ( $\log I)$ vs. logarithm of scan rates (log v) gave straight lines for both modified and bare electrodes (Fig. 3 a and b). The linear equation for MCPE (Eq. 6) and BCPE (Eq. 7) is shown below:

$$
\begin{array}{rc}
\log I_{p a}(\mu A)=0.67 \log v(V / s)+3.192, r^{2}=0.9917 & \text { Eq. } 6 \\
\log I_{p a}(\mu A)=0.43 \log v(V / s)+2.57, r^{2}=0.9627 & \text { Eq. } 7
\end{array}
$$

In BCPE case, a slope of 0.43 (Eq. 7) was obtained, which is close to the theoretical value of 0.5 for a purely diffusion controlled process. In MCPE case, a slope of 0.67 was found. The slope value stands between the theoretical value of 1 for the adsorption process and 0.5 for a diffusion controlled mechanism [20]. It can then be concluded that the redox couple $\left(\mathrm{Fe}^{2+} / \mathrm{Fe}^{3+}\right)$ followed a diffusion mechanism at the BCPE surface and, at MCPE, a combination of diffusion and adsorption procedures.

\section{Calculation of the surface coverage}

To find out the surface coverage of the adsorbed molecule, the following relationship (eq. 8) was proposed for adsorption in cyclic voltammetry [21]:

$$
\mathrm{I}_{\mathrm{p}}=\frac{n^{2} F^{2} \Gamma A u}{4 R T}
$$

Eq. 8 
where $\Gamma$ is the surface coverage of the adsorbed molecule (in $\mathrm{mol} / \mathrm{cm}^{2}$ ), and the other parameters are commonly known in their values, as discussed above.

The plot of peak current $(\mu \mathrm{A})$ and scan rate $(\mathrm{mV} / \mathrm{s})$ gave the following equation for modified (Eq. 9) and bare electrodes (Eq. 10) and, from the slope value of these equations, the surface coverage was calculated.

$$
\begin{aligned}
I_{p}(\mu A)=2.0335 v(\mathrm{mV} / \mathrm{s})+110.38, r^{2}=0.9738 & \text { Eq. } 9 \\
I_{p}(\mu A)=0.519 v(\mathrm{mV} / \mathrm{s})+83.2, r^{2}=0.8845 & \text { Eq. } 10
\end{aligned}
$$

The surface coverage for MCPE and BCPE was calculated, being $3.77 \times 10^{-6}$ $\mathrm{mol} / \mathrm{cm}^{2}$ and $2.73 \times 10^{-6} \mathrm{~mol} / \mathrm{cm}^{2}$, respectively.
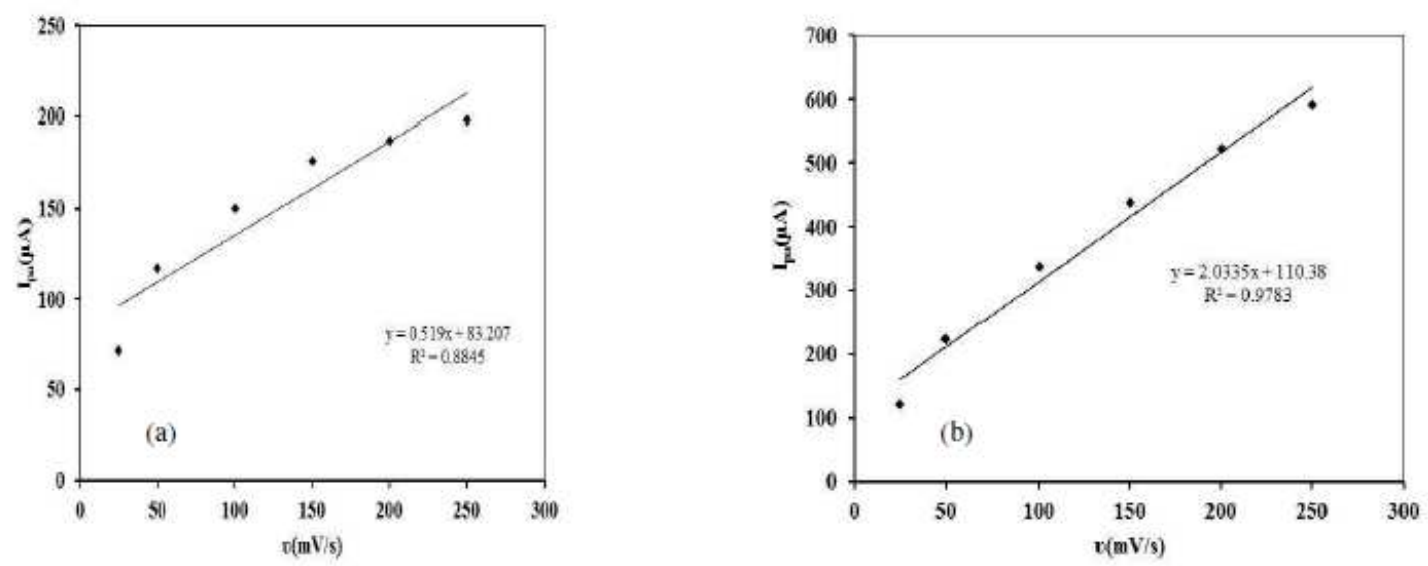

Figure 4. Plot between peak current $(\mu \mathrm{A})$ and scan rate $(\mathrm{mV} / \mathrm{s})$ for (a) modified and (b) bare carbon paste electrodes.

Fig. $4 \mathrm{a}$ and $\mathrm{b}$ showed these plots, and it can be seen that a plot of peak current $(\mu \mathrm{A})$ and scan rate $(\mathrm{mV} / \mathrm{s})$ for MCPE yield a straight line, while it followed a curvature path in the case of BCPE. This further confirmed the above explanation that a diffusion process occurred at BCPE, and that at MCPE there was a combination of both diffusion and adsorption processes.

Nature of the electrode's process

The relationship of scan rate $(\mathrm{mV} / \mathrm{s})$ and $\mathrm{Ip} / \mathrm{v}^{1 / 2}$ is often used as a diagnostic criterion for identifying the nature of the electrode process. For the modified and bare electrodes, a plot of scan rate-normalized current versus scan rate exhibits an indicative shape typical of EC (Fig. 5a) and ECE processes (Fig. 5b).

Moreover, the ratio of peak current $\left(\mathrm{I}_{\mathrm{pa}} / \mathrm{I}_{\mathrm{pc}}\right)$ (Table 1) increased with an increasing scan rate for $P$. cruentum modified electrode, and vice-versa for the bare electrode. This further confirmed that the nature of electrode's process is EC in the modified electrode [22], while it is ECE in the case of the bare one [23]. 

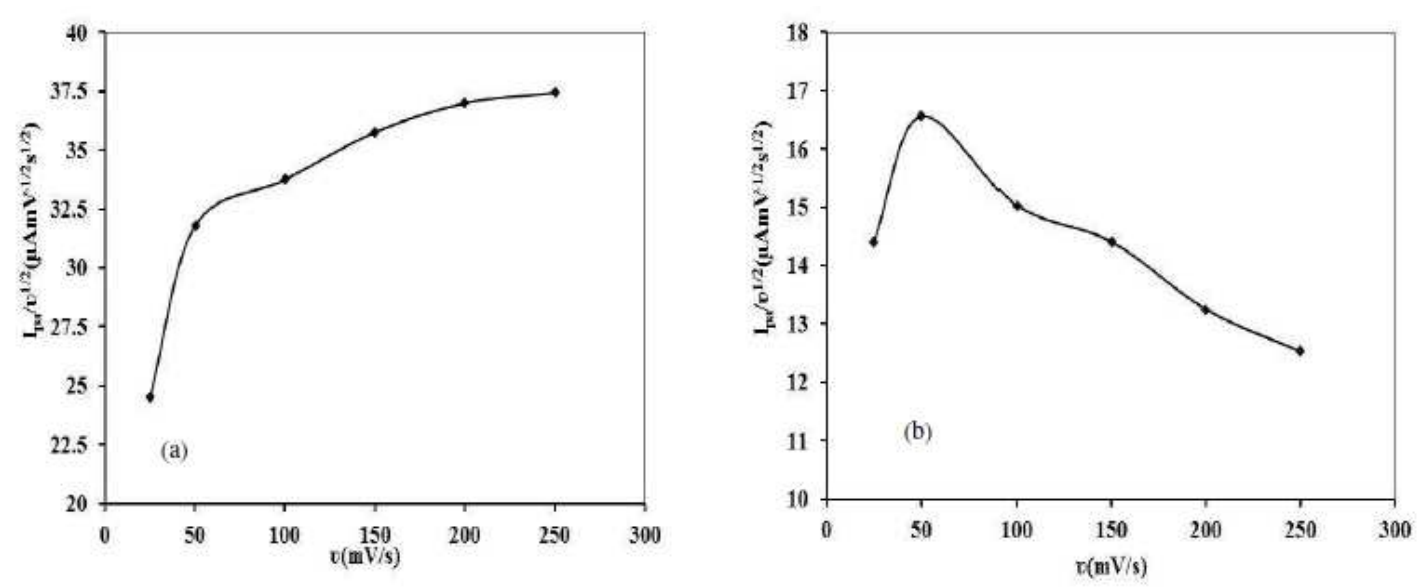

Figure 5. Variation of peak current function $\left(\mathrm{I}_{\mathrm{p}} / \mathrm{v}^{1 / 2}\right)\left(\mu \mathrm{A} \mathrm{mV}^{-1 / 2} \mathrm{~s}^{1 / 2}\right)$ with scan rate $(\mathrm{mV} / \mathrm{s})$ for (a) modified and (b) bare carbon paste electrodes.

Table 1. Peak current ratio $\left(\mathrm{I}_{\mathrm{pa}} / \mathrm{I}_{\mathrm{pc}}\right)$ for bare and modified electrodes.

\begin{tabular}{cc}
\hline \multicolumn{2}{c}{ Peak current ratio $\left(\mathbf{I}_{\mathbf{p a}} / \mathbf{I}_{\mathbf{p c}}\right)$} \\
\hline Bare electrode & Modified electrode \\
\hline 0.61 & 0.74 \\
\hline 0.82 & 0.91 \\
\hline 0.83 & 0.88 \\
\hline 0.85 & 0.92 \\
\hline 0.80 & 0.94 \\
\hline 0.77 & 0.95 \\
\hline
\end{tabular}

Calculation of kinetic parameters

The kinetic behavior was analyzed by studying the relationship between peak potential $\left(E_{\mathrm{p}}\right)$ and logarithm of scan rate $(\log v)$, as the peak potential of the oxidation and reduction peak is dependent on the scan rate, and it allowed calculation of the charge transfer coefficient $(\alpha)$.

From Fig. 6 a and b, a linear relationship was observed fulfilling the following equations (Eqs. 11 and 12) between the $\log$ of scan rate and $E_{p}$ for modified and bare electrodes.

$$
\begin{gathered}
\mathbf{E}_{\mathrm{p}}(\mathrm{V})=-0.1073 \log v(V / s)-0.0573, r^{2}=0.9432 \\
\mathrm{E}_{\mathrm{p}}(V)=0.11 \log v(V / s)+0.4416, r^{2}=0.9987
\end{gathered}
$$

According to Laviron [24], the slope of plot $\mathrm{E}_{\mathrm{p}} \mathrm{vs}$. $\log \mathrm{v}$ is equal to $2.3 \mathrm{RT} / \alpha \mathrm{nF}$ or 2.3RT/ $(1-\alpha) \mathrm{nF}$ for cathodic and anodic peaks, respectively. Using the slope value of the plots from Eq. 11 and 12, the value of $\alpha$ is found to be 0.549 and 0.536 for modified and bare electrodes. As this is one electron system $(n=1)$, the value of charge transfer coefficient remains the same.

Heterogeneous electron transfer rate constant $\left(\mathrm{k}_{\mathrm{s}}\right)$ is calculated by applying the following formula [25]:

$$
\mathrm{k}_{\varepsilon}=\frac{n F \alpha \mathrm{v}_{a}}{R T}=\frac{n F(1-\alpha) \mathrm{v}_{\sigma}}{R T}
$$


where $v_{c}$ and $v_{a}$ are the potential scan rates at the intercept of the straight line which fits to anodic and cathodic data, respectively. These potential scan rates can be calculated from the graph plotted between $\Delta \mathrm{E}\left(\mathrm{E}_{\mathrm{p}}-\mathrm{E}^{0}\right.$, where $\mathrm{E}^{0}$ is the formal electrode potential) and the logarithm of scan rate (Fig. 6c and $d$ ). Initially, the value of $\Delta \mathrm{E}$ is independent of the scan rate, indicating a fast charge transfer; however, at high scan rates, the peak separation undergoes an increase, indicating a limitation due to charge transfer kinetics. The value of $\mathrm{k}_{\mathrm{s}}$ is determined to be $27.79 \mathrm{~s}^{-1}$ and $24.33 \mathrm{~s}^{-1}$ for MCPE and BCPE. The calculated values of $\alpha$ and $\mathrm{k}_{\mathrm{s}}$ for both the electrodes indicate that the electronic communication between the redox system and surface of electrode is fast.
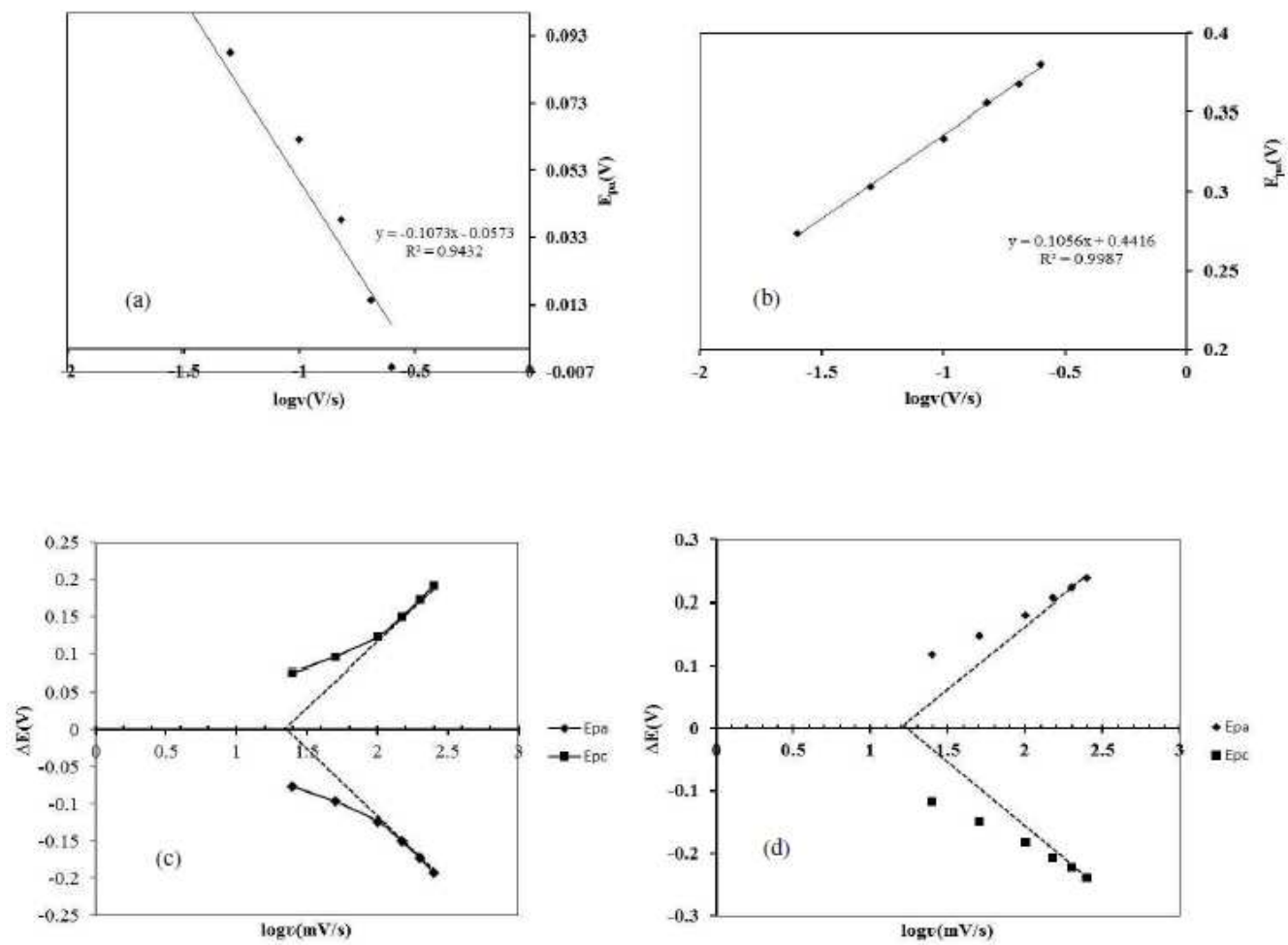

Figure 6. Plot between peak potential (V) and logarithm of scan rate (V/s) for (a) modified and (b) bare carbon paste electrodes. Plot between peak potential separation (V) and logarithm of scan rate $(\mathrm{mV} / \mathrm{s})$ for (c) modified and (d) bare carbon paste electrodes.

\section{Conclusion}

In the present study, the electrochemical characterization of $P$. cruentum modified carbon paste electrode was performed with cyclic voltammetry. These measurements showed that the electro catalytic response of the modified carbon paste electrode was improved in comparison to the bare one. FTIR spectra of the modified electrode showed greater number of absorption bands. A modified carbon paste electrode has a higher electrochemical surface area with a greater surface coverage capacity. Calculation of kinetic parameters (rate constant and charge transfer) also predicted that a modified electrode has faster electron transfer kinetics than a bare one. This reveals that $P$. cruentum has endowed the 
carbon paste with better electro analytical efficiency, which has been and will be further employed for practical purposes.

\section{References}

1. Ma J, Sengupta MK, Yuan D, et al. Anal Chim Acta. 2014; 1: 831.

2. Wang J. Analytical Electrochemistry. 3rd ed. New York: Wiley-VCH; 2000.

3. Martin-Yerga D, Gonzalez-Garcia MB, Costa-Garcia A. Talanta. 2013; 116: 109.

4. Kalcher K, Švancara I, Metelka R, et al. in: The Encyclopedia of Sensors. Grimes CA, Dickey EC, Pishko MV. Editors. Stevenson Ranch, CA: ASP Publishers; 2006. p 283.

5. Stanic Z, Girousi S. in: Sensing in Electroanalysis. Kalcher K, Metelka R, Svancara I, et al. Editors. Pardubice: University Press Centre; 2011. p 89.

6. Svancara I, Vytras K, Barek J, et al. Critical Rev Anal Chem. 2001; 31: 311.

7. Kalcher K, Kauffmann JM, Wang J, et al. Electroanalysis. 1995; 7: 5.

8. Kalcher K. Electroanalysis. 1990; 2: 419.

9. Wang J, Chen C. Biotechnol Adv. 2009; 27: 195.

10. Frurest F, Volesky H. App Biochem Biotechnol. 1997; 67: 215.

11. Zaib M, Saeed A, Hussain I, et al. Biosens Bioelectron. 2014; 62: 242.

12. Taurino I, Carrara S, Giorcelli M, et al. Surface Sci. 2012; 606: 156.

13. Andrieux CP, Blocman C, Dumas-Bouchiat JM, et al. J Electroanal Chem Interfacial Electrochem. 1980; 113: 12.

14. Majumdar A, Scholz G, Hippler R. Surface Coatings Technol. 2009; 203: 2013.

15. Coates J. in: Encyclopedia of Analytical Chemistry. Meyers RA. Editor. Chichester: John Wiley \& Sons Ltd; 2000. p 10815.

16. Hassaninejad-Darzi SK, Rahimnejad M. J Iran Chem Soc. 2014; 11: 1047.

17. Rezaei B, Damiri S. Sens Actuators B. 2008; 134: 324.

18. Southampton electrochemistry group. Instrumental Methods in Electrochemistry. 1st ed. Chichester: Ellis Horwood Ltd; 1990.

19. Antonio TRTA, Basso CR, Cabral MF, et al. Int J Electrochem Sci. 2013; 8: 4150.

20. Ozturk F, Tasdemir IH, Erdogan DA, et al. Acta Chim Slov. 2011; 58: 830.

21. Barek J, Peckova K, Vyskocil V. Current Anal Chem. 2008; 4: 242.

22. Liu S, Ju H. Analyst. 2003; 128: 1420.

23. Shaikh AA, Begum M, Khan AH, et al. Russ J Electrochem. 2006; 42: 620.

24. Laviron E. J Electroanal Chem. 1979; 101: 19.

25. Sempionatto JR, Recco LC, Pedrosa VA, et al. Chem Soc. 2014; 25: 453. 